\title{
Ultrasound findings in a case of Eales' disease and ocular trauma with anterior chamber cholesterolosis
}

\author{
Peng Lu and Jingjing Huang ${ }^{*}$ (D)
}

\begin{abstract}
Background: Anterior chamber cholesterolosis is a rare phenomenon which occurs mostly in chronically blind eyes. We present the anterior and posterior ultrasound findings in a case of anterior chamber cholesterolosis secondary to Eales' disease and ocular trauma, which may contribute to the understanding of the potential mechanism of this phenomenon.
\end{abstract}

Case presentation: A 48-year-old man presented with "sparking" right eye, which appeared soon after the ocular trauma. Both eyes were confirmed Eales' disease in our center 8 years ago, and right eye remained no light perception since then. Intraocular pressure of right eye measured by Goldmann applanation tonometry was 1 $\mathrm{mmHg}$. Slitlamp photograph revealed multiple polychromatic large crystals in anterior chamber. Ultrasound biomicroscopy showed that anterior chamber was filled with extensive large granular substances. Dense dotted hyperechoic foci and retinal detachment was found in B-scan ultrasound examination. The right eye was diagnosed as anterior chamber cholesterolosis secondary to Eales' disease and ocular trauma. The patient was asymptomatic, and therefore was advised to have regular follow-up.

Conclusion: The findings of above imaging examinations, as well as complaint of "sparkling" eye appeared soon after ocular trauma elucidate that anterior chamber cholesterol crystals were from vitreous cavity. Any factors facilitating the communication of anterior chamber and vitreous body may lead to the occurrence of this rare phenomenon in predisposing eyes. The anterior and posterior ultrasound findings may give a clue on the potential mechanism.

Keywords: Cholesterolosis, Cholesterol crystal, Eales' disease, Ocular trauma, Ultrasound

\section{Background}

Anterior chamber cholesterolosis, with polychromatic shining crystals presenting in anterior chamber, is an interesting and uncommon condition which can occur in eyes suffering from vitreous hemorrhage, hyphema, long-standing retinal detachment, chronic intraocular inflammation, and Coats disease [1-5]. Anterior chamber cholesterolosis secondary to Eales' disease is extremely

\footnotetext{
* Correspondence: hjijing@mail.sysu.edu.cn Guangzhou 510623, China

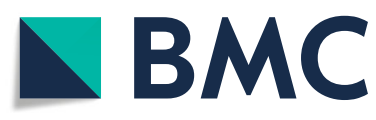

State Key Laboratory of Ophthalmology, Department of Glaucoma, Zhongshan Ophthalmic Center, Sun Yat-sen University, 7 Jinsui Road,

( ) The Author(s). 2020 Open Access This article is licensed under a Creative Commons Attribution 4.0 International License, which permits use, sharing, adaptation, distribution and reproduction in any medium or format, as long as you give appropriate credit to the original author(s) and the source, provide a link to the Creative Commons licence, and indicate if changes were made. The images or other third party material in this article are included in the article's Creative Commons licence, unless indicated otherwise in a credit line to the material. If material is not included in the article's Creative Commons licence and your intended use is not permitted by statutory regulation or exceeds the permitted use, you will need to obtain permission directly from the copyright holder. To view a copy of this licence, visit http://creativecommons.org/licenses/by/4.0/. The Creative Commons Public Domain Dedication waiver (http://creativecommons.org/publicdomain/zero/1.0/) applies to the data made available in this article, unless otherwise stated in a credit line to the data. derstanding of this phenomenon [6].

We report a case of anterior chamber cholesterolosis in a 48-year-old patient suffered from Eales' diseases and ocular trauma, showing the anterior and posterior ultrasound findings. Notably, this is the first description of the characteristics of ultrasound biomicroscopy (UBM) findings of anterior chamber cholesterolosis. The case report may enable us to understand the potential mechanism of this phenomenon. 

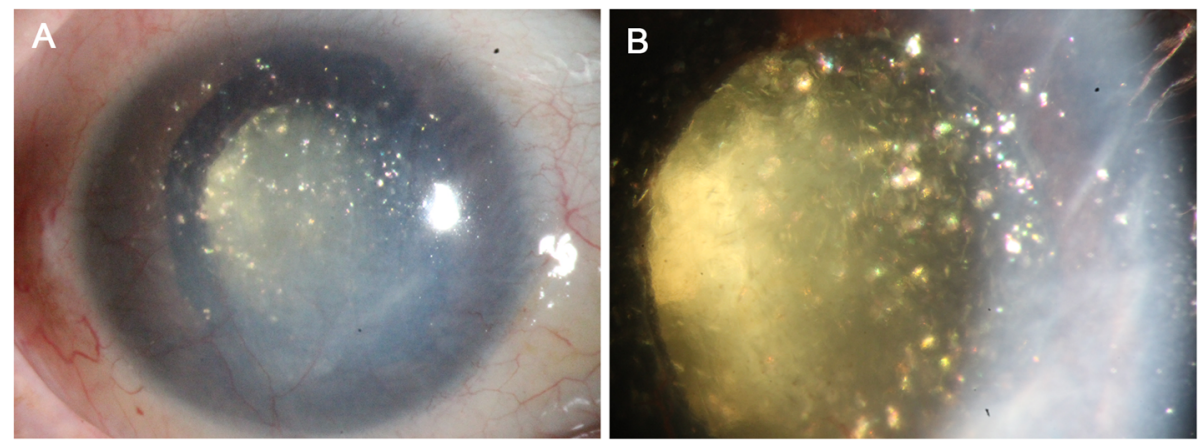

Fig. 1 Slitlamp photograph of right eye showed multiple polychromatic shining crystals drifting in anterior chamber

\section{Case presentation}

A 48-year-old man presented with "sparkling" right eye for 1 year, without redness and pain. His right eye was punched by a hoe 1 year ago and remained untreated. Soon after that, the affected eye showed "sparking" appearance.

According to his medical record documented 8 years ago, his right eye remained no light perception since then, and intraocular pressure was high $(57 \mathrm{mmHg})$ due to neovascular glaucoma. Dilated fundus examination and B-scan ultrasound indicated vitreous hemorrhage, while retinal detachment was not found. Fundus fluorescein angiography (FFA) revealed engorged tortuous veins, diffused vascular occlusion area and lots of microangiomas on the edge of inferior-nasal occlusion area in the right eye, and slightly engorged tortuous veins with increased permeability in the left eye. The patient reported no systemic diseases such as hypertension, diabetes mellitus, sickle cell disease. The diagnosis of Coat's disease, retinal vein occlusion, diabetic retinopathy and sickle cell disease were excluded according to the fundus examination, FFA results and medical history [7, 8]. A final diagnosis of Eales' disease on both eyes and neovascular glaucoma on right eye was made. Right eye was treated with photocoagulation, and systemic and topical anti-glaucoma therapy. The patient did not come back to follow up until 8 years later.
At the current visit, right eye was no light perception and intraocular pressure measured by Goldmann applanation tonometry was $1 \mathrm{mmHg}$. On examination, multiple polychromatic glistening large crystals were found to float in the slightly straw yellow-colored fluid (Fig. 1). As shown in UBM examination, the central anterior chamber depth is $3.83 \mathrm{~mm}$, which is much larger when compared with the contralateral eye $(2.75 \mathrm{~mm})$, anterior chamber angle is closed in all positions, iris are markedly thin and stiff, masses of large granular substances exist in the anterior chamber (Fig. 2a), the ciliary body and anterior choroid are detached (Fig. 2b). B-scan ultrasound examination revealed dense dotted hyperechoic foci and retinal detachment (Fig. 3). The patient was diagnosed with anterior chamber cholesterolosis secondary to Eales' disease and ocular trauma in his right eye based on the above findings. However, the right eye was no light perception and asymptomatic, the patient was advised to have regular follow-up.

\section{Discussion and conclusions}

Anterior chamber cholesterolosis is a secondary phenomenon which can rarely occur in blind eyes suffering from severe ocular trauma or degenerative ocular diseases, for example, Coats' disease [1, 2]. Unlike Coats' disease, Eales' disease is an idiopathic retinal periphlebitis characterized by three basic pathological changes:
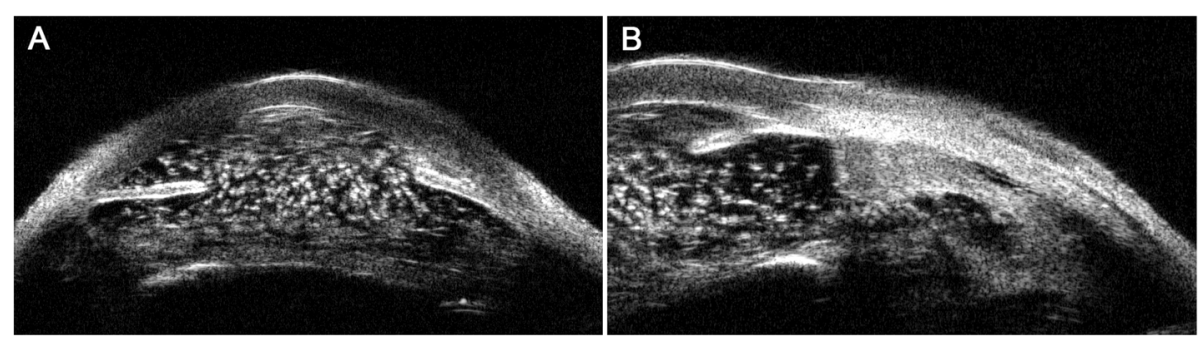

Fig. 2 Ultrasound biomicroscopy of right eye revealed (a) anterior chamber was filled with granular substances and (b) detachment of ciliary body 

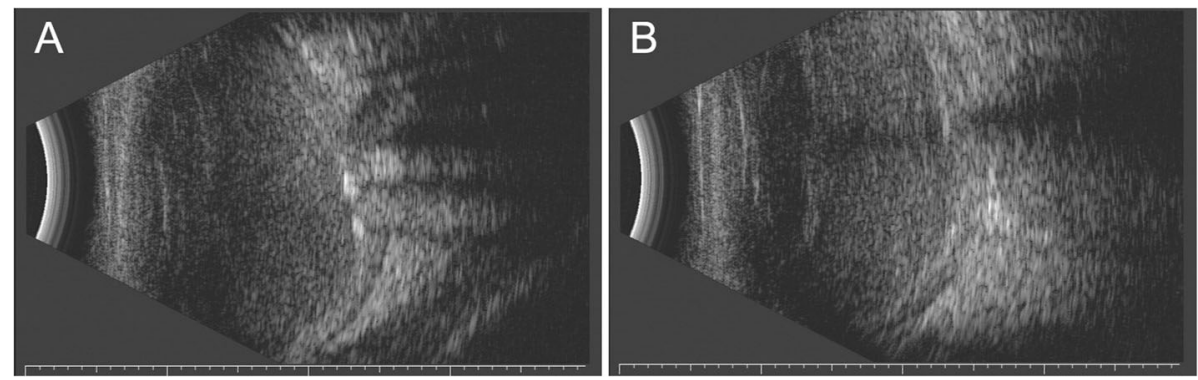

Fig. 3 B-scan ultrasound of right eye revealed dense dotted hyperechoic foci in vitreous cavity and retinal detachment

inflammation, ischemia, and neovascularization [9]. Ocular ischemia caused by Eales' disease may account for the development of neovascular glaucoma in this case. Recurrent vitreous hemorrhage from retinal neovascularization is a hallmark of Eales' disease and may lead to tractional or combined retinal detachment [9]. The anterior chamber cholesterolosis secondary to Eales' disease is even rarer.

Cholesterol crystals are considered to originate from lipid-rich cell membranes of erythrocytes during the breakdown of vitreous hemorrhage [1]. Long-standing retinal detachment without intraocular hemorrhage may also be the cause of cholesterol crystals formation in some eyes, because subretinal fluid is also rich in lipid [1]. In our case, vitreous hemorrhage caused by Eales' disease and the consequent retinal detachment might together contribute to the formation of cholesterol crystals.

A definite diagnosis of cholesterol crystals can be made through histopathologic examination. Cholesterol crystals will demonstrate birefringence with polarized light and positive staining with lipid stains such as OilRed-O test $[1,10]$. However, clinical diagnosis of cholesterol crystals is easy to make because of its typical characteristics and limited differential diagnosis including calcium oxalate crystals, proteinaceous crystals and aqueous cells. Cholesterol crystals are multicolored and much larger than the above three substances [1]. In addition, proteinaceous crystals and aqueous cells tend to occur in phacolysis, but cholesterol crystals are usually found in chronically blind eyes [1]. Anterior chamber cholesterol crystals of our case revealed by slitlamp photograph were in line with previous studies $[1,10]$. Notably, masses of large granular substances as shown in UBM images of the current case might further support the diagnosis of anterior chamber cholesterolosis.

A hypothesis for the pathogenesis of anterior chamber cholesterolosis is that cholesterol crystals have already formed in the vitreous cavity, and ocular trauma, which may lead to the dysfunction of suspensory ligament and subsequent lens (sub) luxation, will allow cholesterol crystals entering anterior chamber from vitreous cavity
[1-3]. Asymmetry of the central anterior chamber depth is an important clinical feature of the lens subluxation [11]. Our patient suffered from an ocular trauma, which could be a trigger factor, and showed a significant difference in the depth of central anterior chamber $(3.83 \mathrm{~mm}$ of the affected eye vs. $2.75 \mathrm{~mm}$ of the unaffected eye), and masses of large granular substances in the anterior chamber without any lens echo in the UBM images. The asymmetry of the central anterior chamber depth of the current case might be caused by lens subluxation or the absorption of lens. The findings of B-scan ultrasound showed extensive hyperechoic foci in vitreous body. Additionally, glistening substances were found in anterior chamber soon after the ocular trauma. Taking all together, our case may evidence this hypothesis.

Secondary glaucoma is a common complication of anterior chamber cholesterolosis and occurred in most previously reported cases [5, 12]. However, the intraocular pressure of the current case was low, probably because of the detachment and degeneration of the ciliary body.

In conclusion, cholesterol crystals may have already existed in the vitreous body of predisposing eyes. Any factors that can facilitate the communication of the anterior chamber and vitreous body may lead to the occurrence of anterior chamber cholesterolosis. The non-invasive UBM examination can demonstrate the characteristics of anterior chamber cholesterolosis and help us understand this rare phenomenon.

\section{Abbreviations}

UBM: Ultrasound biomicroscopy; FFA: Fundus fluorescein angiography

\section{Acknowledgements \\ Not Applicable.}

\section{Authors' contributions}

$\mathrm{PL}$ collected the data and wrote the manuscript. JH performed diagnosis and medical treatment for the patients, interpreted the data and revised the manuscript. Both authors read and approved the final manuscript.

\section{Funding}

This work was supported by the National Natural Science Foundation of China (81670850). The funding organization had no role in the study design, data collection, analysis, interpretation, nor manuscript preparation. 


\section{Availability of data and materials}

Data sharing is not applicable to this article as no datasets were generated

or analysed during the current study.

\section{Ethics approval and consent to participate}

Not applicable.

\section{Consent for publication}

The patient agreed to publish the clinical data and signed the consent form.

\section{Competing interests}

The authors declare that they have no competing interest.

Received: 1 October 2019 Accepted: 24 September 2020

Published online: 06 October 2020

\section{References}

1. Kennedy CJ. The pathogenesis of polychromatic cholesterol crystals in the anterior chamber. Aust N Z J Ophthalmol. 1996;24:267-73.

2. Stacey AW, Borri M, Francesco SD, Antenore AS, Menicacci F, Hadjistilianou T. A case of anterior chamber Cholesterolosis due to Coats' disease and a review of reported cases. Open Ophthalmol J. 2016;10:27-32.

3. Shields JA, Eagle RC Jr, Fammartino J, Shields CL, De Potter P. Coats' disease as a cause of anterior chamber cholesterolosis. Arch Ophthalmol. 1995;113: 975-7.

4. Khan IJ, Parulekar MV. Intraocular cholesterol crystals. Postgrad Med J. 2014; 90:58-9.

5. Rishi P, Rishi E, Devulapally S. Cholesterolosis Bulbi. JAMA Ophthalmol. 2017: 135:e165458.

6. Mishra RK, Ghosh M, Ghosh A. Cholesterol crystals in Eales' disease. Indian J Ophthalmol. 1980;28:67-8.

7. Shields JA, Shields CL, Honavar SG, Demirci H. Clinical variations and complications of coats disease in 150 cases: the 2000 Sanford Gifford memorial lecture. Am J Ophthalmol. 2001;131:561-71.

8. Flaxel CJ, Adelman RA, Bailey ST, Fawzi A, Lim Jl, Vemulakonda GA, et al. Retinal vein occlusions preferred practice pattern. Ophthalmology. 2020;127: P288-320.

9. Das T, Pathengay A, Hussain N, Biswas J. Eales' disease: diagnosis and management. Eye (Lond). 2010;24:472-82

10. Wand M, Gorn RA. Cholesterolosis of the anterior chamber. Am J Ophthalmol. 1974;78:143-4.

11. Luo L, Li M, Zhong Y, Cheng B, Liu X. Evaluation of secondary glaucoma associated with subluxated lens misdiagnosed as acute primary angleclosure glaucoma. J Glaucoma. 2013:22:307-10.

12. Gupta N, Beri S, D'souza P. Cholesterolosis Bulbi of the anterior chamber in coats disease. J Pediatr Ophthalmol Strabismus. 2009:48:E1-3.

\section{Publisher's Note}

Springer Nature remains neutral with regard to jurisdictional claims in published maps and institutional affiliations. 